July 2009

\title{
Persistent lithium-induced neurotoxicity: direct effect of lithium and/or hypernatremia?
}

\author{
Ioana-Mihaela Popescu \\ University of California - San Francisco, ioana.md@gmail.com \\ James A. Bourgeois \\ University of California, Davis
}

Follow this and additional works at: https://jdc.jefferson.edu/jeffjpsychiatry

Part of the Psychiatry Commons

Let us know how access to this document benefits you

\section{Recommended Citation}

Popescu, loana-Mihaela and Bourgeois, James A. (2009) "Persistent lithium-induced neurotoxicity: direct effect of lithium and/or hypernatremia?," Jefferson Journal of Psychiatry. Vol. 22 : Iss. 1 , Article 3.

DOI: https://doi.org/10.29046/JJP.022.1.003

Available at: https://jdc.jefferson.edu/jeffjpsychiatry/vol22/iss1/3

This Article is brought to you for free and open access by the Jefferson Digital Commons. The Jefferson Digital Commons is a service of Thomas Jefferson University's Center for Teaching and Learning (CTL). The Commons is a showcase for Jefferson books and journals, peer-reviewed scholarly publications, unique historical collections from the University archives, and teaching tools. The Jefferson Digital Commons allows researchers and interested readers anywhere in the world to learn about and keep up to date with Jefferson scholarship. This article has been accepted for inclusion in Jefferson Journal of Psychiatry by an authorized administrator of the Jefferson Digital Commons. For more information, please contact: JeffersonDigitalCommons@jefferson.edu. 
Persistent lithium-induced neurotoxicity: direct effect of lithium and/or hypernatremia?

\subsubsection{8}

Case report

A 54-year-old African-American woman was brought to the emergency department of a university medical center with increased confusion. Over several days prior to presentation, she had become drowsy and disoriented. On the day of her admission she had her clothes on inside out. She did not have any nausea, vomiting or diarrhea, and there were no recent changes in her medications. She was previously diagnosed with bipolar disorder type I, and her medications were lithium carbonate extended-release 450 $\mathrm{mg}$ at nighttime, valproic acid $500 \mathrm{mg}$ bid, fluphenazine $30 \mathrm{mg}$ bid, and benztropine $2 \mathrm{mg}$ bid. She had had prior episodes of lithium toxicity. The patient was followed in a community mental health center and, unfortunately, no information was available about how her previous episodes of lithium toxicity were characterized, and more importantly why the lithium was reinstated by her outpatient psychiatrist following these episodes. Physical examination showed a fine resting tremor. The patient was afebrile, with blood pressure of 124/73 mm Hg and pulse of 104 BPM. Initial serum electrolytes were unremarkable (including $\mathrm{Na}+$ of $143 \mathrm{mmol} / \mathrm{L}$ ), but the creatinine was $2.3 \mathrm{mg} / \mathrm{dL}$. Creatine kinase, ammonia, TSH, folate, vitamin B12 were unremarkable, and WBC count was 12.7 (cells x 1000/microliter). Serum lithium level was $2.4 \mathrm{mEq} / \mathrm{L}$, and valproic acid level was $48 \mathrm{mEq} / \mathrm{L}$.

Computed tomography (CT) of the head revealed only mild cerebral atrophy. A psychosomatic medicine consultation was accomplished. On examination, the patient was 
disheveled, alert, with poor eye contact, and disoriented to time and place. Speech was mildly dysarthric. She had bilateral mild tremor of the upper extremities. Psychiatric diagnoses were delirium, secondary to lithium intoxication, and bipolar disorder, type I. Lithium, fluphenazine, and benztropine were stopped, valproate was continued, and she was admitted to the internal medicine service.

During the next first 24 hours of hospitalization, the patient had increasing shortness of breath and became obtunded. A Foley catheter was placed and 3 liters of urine were obtained. Repeated physical examination indicated decreased level of consciousness with lack of response to painful stimuli, tachypnea, and tachycardia. Serum sodium was now increased to $168 \mathrm{mmol} / \mathrm{L}$, creatinine was $2.3 \mathrm{mg} / \mathrm{dL}$, urine osmolality was $147 \mathrm{mOsm} / \mathrm{kg}$, urine $\mathrm{Na}+$ was $42 \mathrm{mmol} / \mathrm{L}$, and lithium level was $2.2 \mathrm{mEq} / \mathrm{L}$. The new severe hypernatraemia was felt to be due to nephrogenic diabetes insipidus (NDI) secondary to lithium toxicity. The patient was transferred to medical intensive care unit (MICU).

In the MICU, a free water deficit (6 liters) was replaced over the next 36 hours, with normalization of her sodium. The free water deficit was replaced as $200 \mathrm{cc}$ free water per hour through her NG tube and $150 \mathrm{cc} / \mathrm{HR}$ plus urine losses through IV fluids with $1 \frac{2}{2}$ normal saline. The sodium level was monitored every four hours and was corrected at a rate averaging less than or equal to $1 \mathrm{mmol} / \mathrm{L}$ per hour. The lithium level decreased steadily but slowly, as she still had a lithium level of $0.3 \mathrm{mEq} / \mathrm{L}$ on her $8^{\text {th }}$ inpatient day. Repeated lithium levels showed $0.2 \mathrm{mEq} / \mathrm{L}$ on her $9^{\text {th }}$ inpatient day, then $0.1 \mathrm{mEq} / \mathrm{L}$ in her $11^{\text {th }}$ and $12^{\text {th }}$ inpatient days. Lithium levels were monitored upon discharge, showing 
a constant level of $<0.1 \mathrm{mEq} / \mathrm{L}$. Her level of alertness slowly improved as her sodium normalized and her lithium finally cleared.

After her ICU stay, she was transferred back to the general medicine floor. Despite her having recovered a full level of consciousness, she was now nonverbal and also presented with new bilateral upper extremity wrist drop. Magnetic resonance imaging (MRI) of the brain, obtained on the $13^{\text {th }}$ hospital day, showed small areas of flair hyperintensity in the left splenium and body of corpus callosum, with a tiny focus in the white matter of left temporal lobe, findings consistent with demyelination. An electroencephalogram (EEG) on the $14^{\text {th }}$ hospital day showed diffuse slowing consistent with generalized encephalopathy, in addition to focal intermittent centrotemporal slowing, and no epileptiform discharges.

A neurological consultation (on the $15^{\text {th }}$ hospital day) demonstrated diffuse hyperreflexia and clonus bilaterally in the lower extremities, bilateral wrist drop, mutism, and frontal release signs. The neurological consultant concluded that her altered neurological status was probably of a toxic/metabolic etiology, given her episode of lithium toxicity and hypernatraemia. An electromyography (EMG) study for the wrist drop indicated no lower motor neuron pathology. Subsequently, a MRI of the spine was ordered, which showed mild multilevel degenerative changes and no evidence of cord abnormality. A medical toxicology consult was called and could find no other toxicity to explain her persistent neuropsychiatric findings beyond the lithium toxicity. 
During the next 20 days of hospital stay the patient started speaking, using short sentences. She showed gradual improvement in her amount of speech and cognitive function. On her $29^{\text {th }}$ hospital day, the patient scored $14 / 25$ (she was unable to attempt the three-step task, copy design, and sentence writing tasks due to persistent weakness of the upper extremities) on the MMSE, with the main impairments in attention, calculation, and recall sections. Throughout her hospitalization, her mood and affect remained well controlled on a therapeutic level of valproate, and she had no motor agitation suggesting a manic episode.

A nephrology consult ( $27^{\text {th }}$ hospital day) reaffirmed the presence of chronic kidney disease, stage III, secondary to lithium toxicity, with tubulointerstitial nephritis. A second EEG done on her $27^{\text {th }}$ hospital day was characterized by the presence of intermittent independent bilateral temporal polymorphic slowing. The neurologist commented that lithium, even at therapeutic levels, can cause pronounced EEG changes. As lithium had been stopped the day of her admission, these changes are still present after one month from its discontinuation. 


\section{Discussion}

Our patient presented with acute neurological changes with an initial lithium level of 2.4 $\mathrm{mEq} / \mathrm{L}$. Cleveland described, for the first time, acute severe neurological disturbance resulting from lithium intoxication, in the absence of gastrointestinal symptoms (1). Our patient also presented with prolonged delirium after lithium was discontinued and hypernatraemia corrected. One week after admission, she presented with diffuse hyperreflexia, clonus, mutism, frontal lobe release signs, and bilateral wrist drop. The MRI of the brain showed changes suggestive of demyelination, while the EMG and MRI of the spine could not explain the wrist drop. The altered mental status was substantiated by the first EEG findings. The second abnormal EEG was consistent with the persistent functional brain changes, lagging well behind the discontinuation of lithium.

A similar case was reported by Lang and Davis, who described a 44 year old man with a two-month history of dysarthria, ataxia and leg weakness, at a serum lithium level of 1.5 $\mathrm{mEq} / \mathrm{L}(2)$. On cessation of lithium, he partially recovered, the main persistent sequelae being cerebellar ataxia. Extensive investigation could find no cause other than chronic lithium toxicity to explain his cerebellar and pyramidal signs, despite serum lithium levels that had been monitored regularly. Another case report described a 60 -year-old man who developed delirium after lithium administration at a serum level of $0.97 \mathrm{mEq} / \mathrm{L}$, and showed persistent delirium for more than 1 month after discontinuation (3). Lithiuminduced delirium generally improves within 1 week after discontinuation (4). It has been reported that abrupt discontinuation of lithium administration induced the development 
and persistence of delirium in patients with serum lithium concentrations within or above the therapeutic range (5).

Lithium toxicity may be life threatening, or result in persistent cognitive and neurological impairment. Hemodialysis is used for severe lithium intoxication, very high serum levels, rising serum levels, or progressive clinical deterioration (6). Although hemodialysis is highly effective in removing circulating lithium, serum concentrations may rebound so repeated or prolonged treatment may be required (7).

Clinical manifestations of lithium toxicity effects may lag behind changes in serum lithium concentrations, due at least in part to delayed distribution into tissues (8). Therefore clinical recovery after lithium intoxication may take several weeks, with neurological symptoms persisting long after lithium levels have normalized. Also the levels of lithium in the blood may not accurately reflect brain lithium levels.

Most episodes of neurotoxicity are reversible on cessation or dose reduction and irreversible lithium toxicity is uncommon (9). Adityanjee described the concept of persisting neurological sequelae of lithium intoxication and named it the syndrome of irreversible lithium-effectuated neurotoxicity (SILENT) (10). In a recent review the same author identified 90 cases of SILENT in peer-reviewed publications, ranging from the typical signs of cerebellar dysfunction to atypical presentations like central pontine myelinosis and retrobulbar optic neuritis (9). The inclusion criteria were 1) causation of these neurological dysfunctions by lithium carbonate in the absence of prior neurological 
illness and 2) the persistence of the sequelae for varying periods beyond two months after the cessation of lithium. Though we followed up this patient for only one month, we can argue that, given the severity of her sequelae, they might well persist beyond the two months criterion for SILENT. Also, the MRI findings suggestive of demyelination resonate with the proposed biologic mechanism of SILENT, which involves demyelination at multiple sites (10).

Our patient experienced hypernatremia, and rapid correction of serum sodium has been implicated as a potent causative factor for central pontine myelinolysis (CPM) and extrapontine myelinolysis (EPM) (11). Those osmotic demyelination syndromes are rapidly progressing, often fatal focal symmetric syndromes, with clinical features ranging from a mild tremor or dysarthria to a progressive quadraparesis and a locked-insyndrome. Our patient did not experience rapid correction of her sodium levels, and also there were no signal changes within the pons on the MRI of the brain, which make a diagnosis of CPM less probable. Also, as evidenced above, cases of SILENT, such as ours can include atypical presentations resembling CPM/EPM (10).

The concurrent psychotropic medications and their pharmacological forms might have played a role in her condition. Our patient was also taking fluphenazine and valproic acid and SILENT was reported in such a case (12). The absorption of slow-release preparations, as our patient's lithium prescription, has been found to be erratic, and can lead to very high lithium concentrations (13). Our patient's gender might have played a 
role too, as both lithium intoxication and neurological sequelae have been observed to be more frequent among women compared with men (14).

Our patient had had previous episodes of lithium toxicity. Chronic lithium poisoning is associated with greater toxicity than that due to acute poisoning in lithium-naive patients (15). In a recent review, the strongest predictors of severe toxicity in chronic lithium poisoning were age $>50$ years, the presence of nephrogenic diabetes insipidis (NDI), hypothyroidism, and impaired renal function, three of which were present in this patient (16). Lithium treatment is the most common cause of drug-induced NDI, affecting about $10 \%$ of patients treated with the drug for 15 years or more (17). The risk of NDI correlates with the duration of lithium therapy and its course is unpredictable even after cessation of the medication. NDI is a relatively rare cause of hypernatraemia caused by urinary losses (18). Our patient may have had previously undiagnosed NDI and on this admission developed hypernatraemia, which contributed to her prolonged altered mental status.

In terms of describing and attributing this patient's unfortunately persistent neurologic deficits following her lithium toxicity episodes, there is a challenge of attributing her symptoms to various disturbances. These include the "direct" CNS effects of lithium (as described in the SILENT syndrome), the effects of the brief (36 hour) period of hypernatremia (presumably from lithium-associated NDI, and excessively rapid correction of the hypernatremia. As the hypernatremia was corrected in a cautious 
fashion, the mechanism of excessively rapid restoration of normal serum sodium levels is unlikely.

Hypernatremia itself, usually due to other factors than lithium-associated NDI, has been associated with neurological deficits, including altered mental status, focal neurologic deficits, agitation, lethargy, neuromuscular hyperactivity, rigidity, hyperreflexia, asterixis, myoclonus, chorea, spasticity, tremor, ataxia, seizures, coma, and death (19-23). CNS symptoms of hypernatremia are more common with serum sodium levels greater than $169 \mathrm{mEq} / \mathrm{L}$ (21). Anatomically, engorged cerebral vasculature, subcortical and subarachnoid hemorrhages, and venous sinus thrombosis have been reported in hypernatremia $(20,22)$.

In our case, we believe the bulk of the clinical evidence suggests neurologic impairment due to the direct neurotoxic effects of lithium, although a contribution to her condition from the brief period of hypernatremia cannot be definitively ruled out. The possible contribution of hypernatremia to our case strongly reinforces the need to closely monitor and manage the serum sodium, not merely the creatinine and lithium levels, in lithium toxicity cases. 


\section{Conclusions}

Psychosomatic medicine psychiatrists are advised to be alert to the possibility of persistent neuropsychiatric sequelae from lithium toxicity in patients presenting with

altered mental status and lithium toxicity. The duration of the lithium toxicity episode and the renal complications of nephrogenic diabetes insipidis and hypernatremia may contribute to the genesis of these complications. EEG, neuroimaging, neurology consultation and toxicology consultation may be needed to fully elucidate these clinical phenomena. 


\section{References}

1. Cleveland SA. A case of poisoning by Lithium: presenting some new features. JAMA 1913;60: 722 .

2. Lang EJ, Davis SM. Lithium neurotoxicity: the development of irreversible neurological impairment despite standard monitoring of serum lithium levels. J Clin Neurosci 2002;9:308-9.

3. Omata N, Murata T, Omori M, Wada Y. A patient with lithium intoxication developing at therapeutic serum lithium levels and persistent delirium after discontinuation of its administration. Gen Hosp Psychiatry 2003;25:53-5.

4. Brown AS, Rosen J. Lithium-induced delirium with therapeutic serum lithium levels: a case report. J Geriatr Psychiatry Neurol 1992;5:53-5.

5. DePaulo JR, Folstein MF, Correa EI. The course of delirium due to Lithium intoxication. J Clin Psychiatry 1982;43:447-9.

6. Jaeger A, Sauder P, Kopferschmitt J, Trisch L, Flesch F. When should dialysis be performed in lithium poisoning? A kinetic study in 14 cases of lithium poisoning. Clin Toxicol 1993;31:429-47. 
7. Waring WS. Management of lithium toxicity. Toxicol Rev 2006;25: 221-30.

8. Clendeninn NJ, Pond SM, Kaysen G, Barraza JJ, Farrell T, Becker CE. Potential pitfalls in the evaluation of the usefulness of hemodialysis for the removal of lithium. J Toxicol Clin Toxicol 1982;19:341-52.

9. Adityanjee, Munshi KR, Thampy A. The syndrome of irreversible lithium-effectuated neurotoxicity. Clin Neuropharmacol 2005;28:38-49.

10. Adityanjee. The syndrome of irreversible lithium effectuated neurotoxicity. J Neurol Neurosurg Psychiatry 1987;50:1246-7.

11. Huq S, Wong M, Chan H, Crimmins D. Osmotic demyelination syndromes: Central and extrapontine myelinolysis. J Clin Neurosci 2007;14:684-8.

12. Normann C, Brandt C, Berger M, Walden J. Delirium \& persistent dyskinesia induced by lithium neuroleptic interaction. Pharmacopsychiatry 1998;31:201-4.

13. Tyrer S, Hullin RP, Birch NJ, Goodwin JC. Absorption of lithium following administration of slow-release and conventional preparations. Psychol Med 1976;6:51-8.

14. Schou M. Long-lasting neurological sequelae after lithium intoxication. Acta Psychiatr Scand 1984;79:594-602. 
15. Waring WS. Delayed cardiotoxicity in chronic lithium poisoning: discrepancy between serum lithium concentrations and clinical status. Basic Clinical Pharmacol Toxicol 2007;100:353-5.

16. Oakley PW, Whyte IM, Carter GL. Lithium toxicity: an iatrogenic problem in susceptible individuals. Aust N Z J Psychiatry 2001;35:833-40.

17. Livingstone $\mathrm{C}$, Rampes H. Lithium: a review of its metabolic adverse effects. J Psychopharmacol 2006;20:347-55.

18. Sze L, Ulrich B, Brandle M. Severe hypernatraemia due to nephrogenic diabetes insipidus - a life-threatening side effect of chronic lithium therapy. Exp Clin Endocrinol Diabetes 2006;114:596-8.

19. Tisdall M, Crocker M, Watkiss J, Smith M: Disturbances of sodium in critically ill adult neurologic patients: a clinical review. J Neurosurg Anesthesiol 2006;18:57-63.

20. Votey SR, Peters AL, Hoffman JR: Disorders of water metabolism: hyponatremia and hypernatremia. Emerg Med Clin North Am 1989;7:749-69.

21. Riggs JE: Neurologic manifestations of electrolyte disturbances. Neurol Clin 2002;20:227-39. 
22. Diringer MN: Management of sodium abnormalities in patients with CNS disease.

Clin Neuropharmacol 1992;15:427-47.

23. Vokes TJ, Robertson GL: Disorders of antidiuretic hormone. Endocrin Metab Clin North Am 1988:17:281-99. 
